Article

\title{
Conventional Industrial Robotics Applied to the Process of Tomato Grafting Using the Splicing Technique
}

\author{
José-Luis Pardo-Alonso ${ }^{1}$, Ángel Carreño-Ortega ${ }^{1, * \mathbb{C}}$, Carolina-Clara Martínez-Gaitán ${ }^{2}$, \\ Iacopo Golasi ${ }^{3}$ (D) and Marta Gómez Galán ${ }^{1}$ \\ 1 Department of Engineering, University of Almería, Research Center CIMEDES, Agrifood Campus of \\ International Excellence (CeiA3), La Cañada de San Urbano, 04120 Almería, Spain; jolupa@ual.es (J.-L.P.-A.); \\ mgg492@ual.es (M.G.G.) \\ 2 Tecnova, Technological Center: Foundation for Auxiliary Technologies for Agriculture; Parque Tecnológico \\ de Almería, Avda. de la Innovación, 23, 04131 Almería, Spain; cmartinez@fundaciontecnova.com \\ 3 DIAEE-Area Fisica Tecnica, Università degli Studi di Roma "Sapienza", 00184 Rome, Italy; \\ iacopo.golasi@uniroma1.it \\ * Correspondence: acarre@ual.es; Tel.: +34-950-214-098
}

Received: 10 November 2019; Accepted: 9 December 2019; Published: 12 December 2019

\begin{abstract}
Horticultural grafting is routinely performed manually, demanding a high degree of concentration and requiring operators to withstand extreme humidity and temperature conditions. This article presents the results derived from adapting the splicing technique for tomato grafting, characterized by the coordinated work of two conventional anthropomorphic industrial robots with the support of low-cost passive auxiliary units for the transportation, handling, and conditioning of the seedlings. This work provides a new approach to improve the efficiency of tomato grafting. Six test rates were analyzed, which allowed the system to be evaluated across 900 grafted units, with gradual increases in the speed of robots work, operating from 80 grafts/hour to over 300 grafts/hour. The results obtained show that a higher number of grafts per hour than the number manually performed by skilled workers could be reached easily, with success rates of approximately $90 \%$ for working speeds around 210-240 grafts/hour.
\end{abstract}

Keywords: tomato grafting; splice grafting technique; agricultural robot; automated grafting; agricultural machinery

\section{Introduction}

The herbaceous graft is a growing technique that allows two pieces of living plant tissue to be joined together in such a way that they will unite and later grow and develop as a single composite plant [1]. This technique is widespread in Southeast Asia, the Mediterranean basin, and Europe for intensive cultivation in tomato greenhouses. With the use of grafting, plants with properties of agronomic interest are created, fundamentally seeking greater resistance to soil diseases and higher productivity in high-quality cultivars [2]. One of the technique's main disadvantages is its high cost of production. The seeds (of both the scions used and the added cost of the rootstock), the cost of labor, the supplies for each graft, the use of machinery and work tools, and post-graft care in the healing chambers are considered the most important factors in price determination [3-5].

It is estimated that the work of the grafting process itself can amount to approximately a quarter of the total costs associated per grafted plant; a third of these costs represent the total cost of the seeds, and the rest is essentially equally divided between the costs of materials and tools, the cost of the clip and the stay in the healing chamber, the energy costs, and the costs of the work of handling and 
transplantation personnel [6,7]. Proportionally, and with respect to the cost of the seeds, the scion represents $80 \%$ of the cost, compared to the $20 \%$ cost of the rootstock (Figure 1 ).

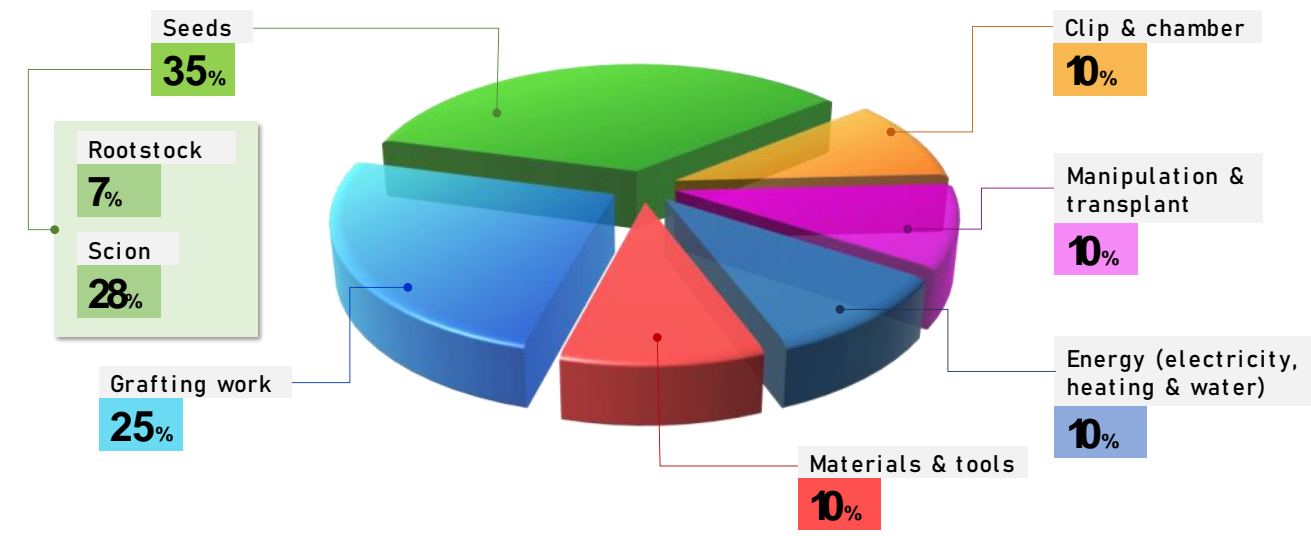

Figure 1. Estimated average cost distribution for a grafted plant. Average data assessed according to data collected in nurseries in Almería (Spain), [6,7].

On the other hand, the average cost of grafted tomato plants versus non-grafted plants varies considerably depending on several factors, mainly the productive scale of the nursery, the cost of labor, the production practices, and the cost of seeds employed, which can sometimes amount to more than $50 \%$ of the total costs [7]. In nurseries with a medium-high production volume, the costs of hand-grafted plants are estimated at approximately $\$ 0.67$ for the USA, compared to $\$ 0.15$ for non-grafted plants [8-10]. Similar prices are maintained for Asian countries, such as Japan and Korea [5], while for Spain and other European countries, the costs vary between $€ 0.54$ for hand-grafted plants compared to $€ 0.18$ for non-grafted plants [11]. These data corroborate that grafted plants can accumulate extra costs 3 to 4 times their cost without grafting.

Even so, the advantages of using grafted plants versus non-grafted plants, which include eliminating the common problems of soil pathogens that have traditionally been controlled by fumigation, have made the technique's use widespread and common in large regions of the world. Grafting has become the most effective and economically viable technique to address this problem [12], compared to other alternatives that have failed to provide a convincing ability to control these diseases, such as genetic improvement with resistance genes, greater crop rotation, soil solarization, the use of plastic mulch, biofumigation, the use of water vapor, crops without soil, the fallow technique, the use of trap plants, or the use of integrated biological control [13]. In Japan, Korea, and the rest of Southeast Asia, grafting is a common technique for the production of Solanaceae, especially in greenhouses, which constitute approximately $100 \%$ of the cultivated area [14]. Although its introduction in Europe and the Mediterranean basin occurred somewhat later, similar graft percentages are reached today. It is estimated that the cost/benefit ratio is 4.6 for grafted tomatoes, compared to 3.5 for non-grafted tomatoes [15].

Grafting is a task that requires considerable time, concentration, and dexterity, even for skilled workers. The delicate characteristics of the process and the biological requirements of the work seedlings, which need to be specially manipulated in a clean, warm, and humid environment, cause growing concern for plant producers due to the lack of available specialized personnel who are capable of facing intense workloads during short campaigns and with a high productive demand. Grafting requires up to three or four people and dedicated specific tasks within the process [3]. The shortage of skilled workers, along with an ageing agricultural population and an increasing demand for grafted plants, has made it necessary to automate grafting [16].

The need to use machinery in plant production to reduce the demand for human labor, expand production capacities, and improve product uniformity has been recognized for a long time [17]. In advanced agricultural countries, efforts are being made to develop and use automatic graft equipment 
due to the lack of labor in rural areas [18,19]. An improvement in grafting methods and techniques that reduce the cost of labor in grafting, its subsequent management, and transplants will contribute to the increased use of grafted plants worldwide [5,17].

There is an important tendency towards developing graft robots with a market potential, as opposed to manual grafting [18]. Splice grafting is a widely used method for Solanaceae, with the advantages of being easily mechanized and having well-defined and clear operations. The stem of the rootstock is cut, preferably below the cotyledons, at a specific angle. The scion, cut with the same angle, has a section that is more or less similar to the rootstock. Finally, by means of a special clamp or clip in the form of a tube, the two cuts are joined [1,20-22] (Figure 2).

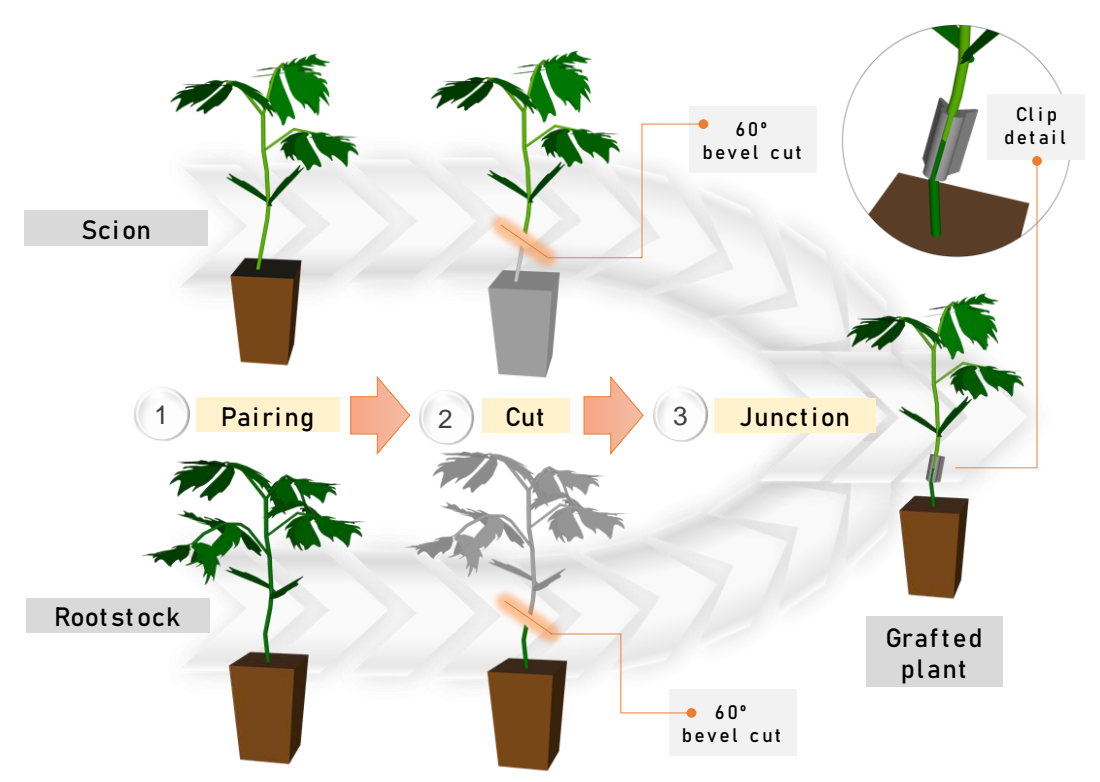

Figure 2. Sketch of the tomato grafting technique known as "tube grafting", "Japanese top-grafting", or "splice grafting".

Since the late 1980s and in the last three decades, there have been numerous attempts to invent equipment that reasonably succeeds in the automated grafting of horticultural plants. In the first two decades, the majority of developments came from Southeast Asia, while in the last decade, developments of mainly European origin have also been added $[3,17,23]$. This equipment has fundamentally been a semi-automated technology system, which facilitates the grafting task but requires up to two or three operators to function. Other developed systems are completely autonomous but enormously rigid in their performance, while at the same time being complex in their adaptability and operational requirements. Faced with these developments, and based on dedicated and specific automation, a study is presented herein of equipment based on conventional industrial robotic technology, supported by simple auxiliary equipment, which allows the productive requirements of the graft task to be met and can be easily adapted to other tasks and productive needs.

The price trend experienced in recent years in industrial robotics, which allows for the acquisition of small robotic units with similar initial investments at a cost no higher than the biannual cost associated with the minimum wage in developed countries [24,25], together with the use of passive auxiliary units with a low cost for transporting, cutting, and placing the binding clip on the seedlings, would allow for a rapid amortization of investment, which makes the study of this development alternative an area of interest.

The objective of this article was centred on the study and feasibility of automated grafting using a robotic cell based on the use of conventional industrial robotics, which allowed the grafting task to be faced with a greater system configurability and flexibility against the natural biological variability of the seedlings being used. This grafting system is supported by the use of simple and low-cost auxiliary 
equipment, which allows the task to be completed with tools external to the logistical tasks of the seedling trays, the cutting of the seedlings, and the dispensing and placement of the graft clip.

\section{Materials and Methods}

\subsection{Device Description and Productive Process}

The robotic equipment for grafting consists of transport devices, the manipulator itself, cutting mechanisms, and devices that facilitate bonding and grip [26]. True to this premise, the study equipment consisted of two anthropomorphic robots equipped with clips adapted for manipulating seedlings, with two seedling bevel cutting devices and a device for the forming, dispensing, and placement of the graft clips (Figure 3).

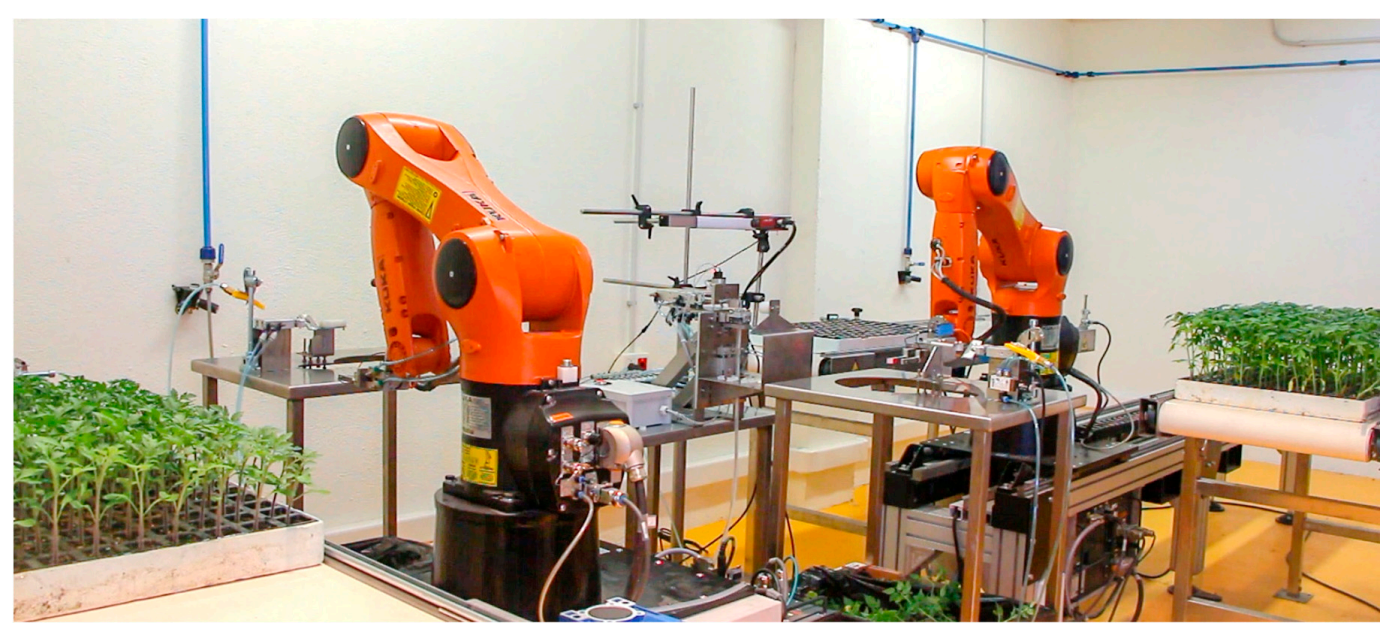

(a)

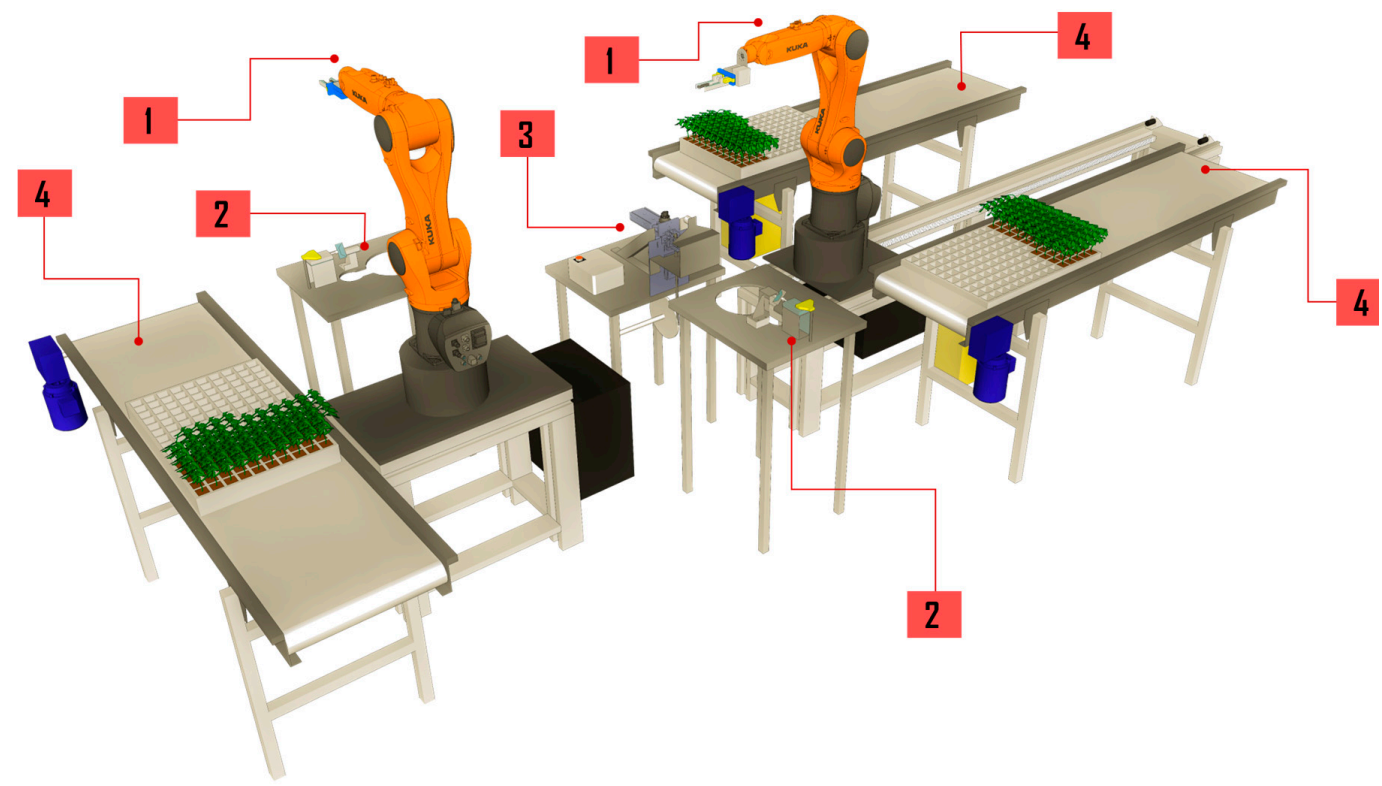

(b)

Figure 3. (a) General view of the robotic cell developed for grafting plants using the splicing technique. (b) Work cell sketch. (1) KUKA KR6 900 robots for manipulating the seedlings. (2) Cutting devices for rootstock and scion seedlings. (3) Forming, dispensing, and placement graft clip device. (4) Conveyor belts for seedling trays (rootstock, scion, and grafted plants). Demonstrative video of the system: https://youtu.be/9GvIDyrBBfo (accessed on 10 December 2019). 
The seedling trays are loaded at the beginning of the process into conveyor belts suitable for this purpose, so that two seedling starter trays, loaded with rootstock and scion seedlings will be properly positioned in front of the working robots.

Each completed row of work is followed by an advance of the belt, which relocates the next row into the appropriate collection area. This process happens until the rows in the seedling starter trays (rootstock and scion) are finished. Likewise, there is a third conveyor belt with an empty output tray for the resulting seedlings to be placed on once grafted. This output conveyor belt also performs partial advances per row while working on that tray.

Once the trays reach the required locations, the two industrial robots, Kuka model Agilus R6 900 (developed by KUKA Roboter $\mathrm{GmbH}$ ), work from their home position in a coordinated manner on the rootstock and scion to achieve graft completion. These robots have equivalent commercial equipment from other large manufacturers worldwide, such as the robot model IRB1200 (developed by ABB), the model MH5F (developed by Yaskawa), or the model LR Mate 200iD/7 L (developed by FANUC). All of them have similar load capacities, degrees of freedom, speeds, and working spaces, so their replacement would not lead to significant differences.

Each robot operates independently by handling each of the seedlings, which are obtained from the input trays. The rootstock and scion seedlings are approached in a simultaneous and coordinated manner: (1) approach the input trays (AIT). This displacement is followed by a precision operation that separates the seedlings from their trays: (2) grip and extraction (GE).

The final elements for the seedling manipulation consist of clamps composed of two fingers with an opening and closing parallel model MHZ2-32D from SMC, equipped with a padded extension zone of low-density (150-200 kg/m ${ }^{3}$ ) polyurethane foam (neoprene) with high resilience for precise and firm seedling attachment. A photocell is located between the ends of these fingers, and a Sick LL3-TB02 optical fibre sensor detects the precise location of the stems of the seedlings, which can emerge at any position within the alveolus of the tray. The individual seedlings have a unique growth morphology, and the alveoli can even be empty (Figure 4).

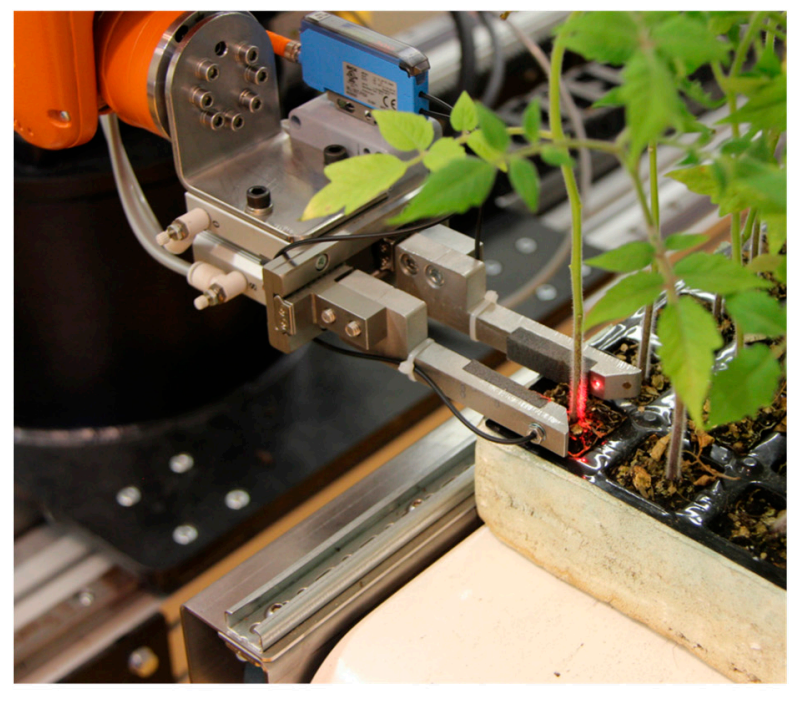

(a)

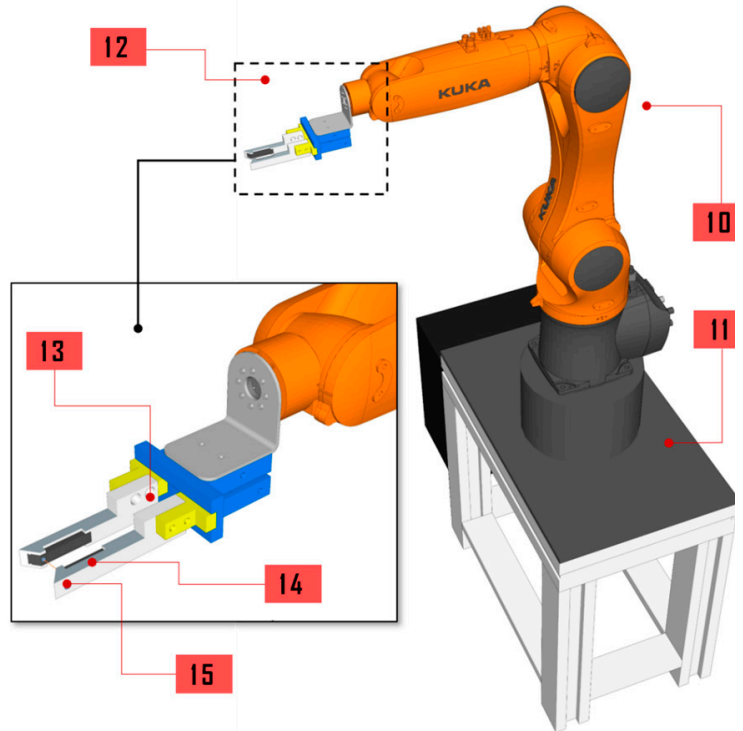

(b)

Figure 4. (a) Detailed view of the clamp or terminal element of the robots. (b) Robot and clamp sketch. (10) Industrial robots. (11) Clamping base. (12) Robot clamp. (13) Fingers with parallel opening and closing operation. (14) Padded area for holding seedlings. (15) Sensor for seedling detection.

After extracting the seedlings from their alveoli in the trays, the robotic arms carry the seedlings to the point where the cut will be made: (3) approach the cutting zone (AC). The system uses two equal 
pieces of equipment for cutting the seedlings to guarantee precision in the required cutting angle and the integrity of the dissected seedling. Both pieces of equipment are responsible for acting, one on the rootstock and another on the scion, allowing the cutting angle to be regulated and complementary between both plants. Prior to cutting, the robots insert the seedlings into a slot or channel located in front of the blade, where the stems are embedded to ensure the verticality of the stems during cutting. The cut is executed by activating a double-shank pneumatic cylinder, SMC model CXSM15-15, coupled to a terminal tool of a sharpened, disinfected, and interchangeable blade of stainless steel with a precise cut angle [27]. The cut is performed by a dry shock stroke of the blade against the seedling, which cleanly bisects the stem and ensures a clean cut: (4) cutting process (C). Meanwhile, an external blower separates the non-useful part of the treated seedling (Figure 5).

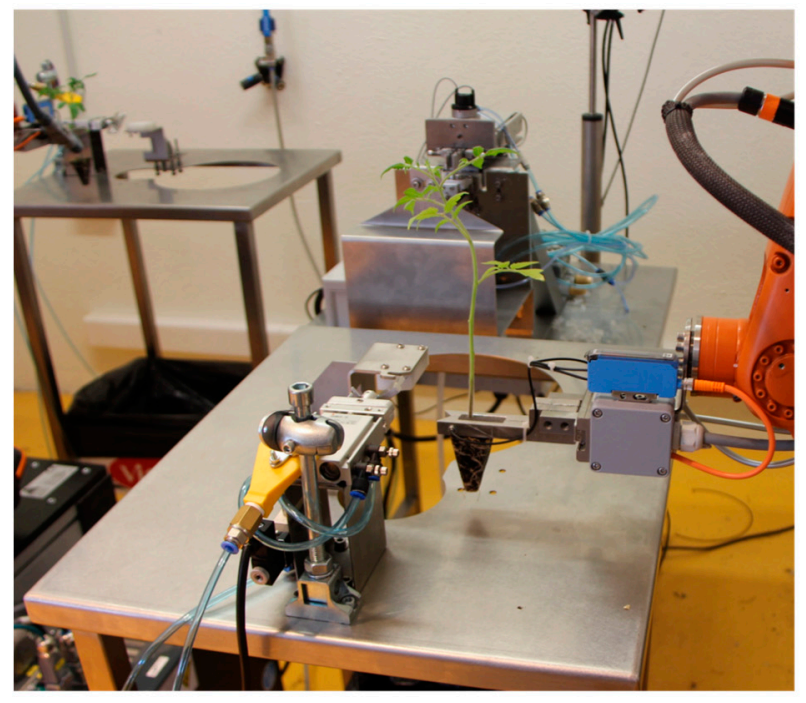

(a)

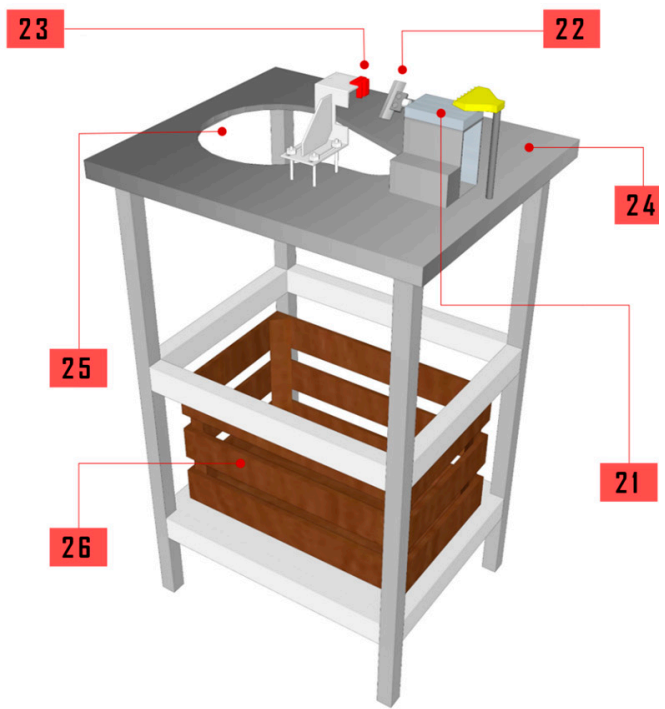

(b)

Figure 5. (a) Detailed view of the cutting device. (b) Cutting device sketch. (21) Pneumatic cylinder to drive the blade. (22) Cutting blade. (23) Slot for seedling lace. (24) Worktable. (25) Hole for waste disposal. (26) Waste accumulation box. (26) Blower.

After the cut, the robotic arms carry the useful parts of the seedlings for the graft towards the bonding area: (5) approach the clip dispensing zone (ACD). The graft equipment that creates the bond is responsible for cutting plastic clips from a continuous roll and then dispensing and placing a clip on the seedlings to be grafted. Thus, this device contains two subsystems: one in charge of preparing the clip and another in charge of placing it.

The first clip preparation subsystem consists of a series of electropneumatic devices that act in a coordinated and sequential manner to perform the clip cutting process from a continuous roll of plastic tube, regulating the advance and thus controlling the length of the cut clips. To obtain a clip with the desired length, an SMC model CJPB10-5 microcylinder presses the plastic tube against the end of a second cylinder, an SMC model CXSM15-15, which advances in the vertical direction the exact length that the clip is desired to have. Finally, an SMC model CXSM15-15 cylinder, equipped with a sharp blade at its end, makes a clean cut with a sharp blow, creating the clip to be used.

The second subsystem contains a rotating cylinder, a Festo model DM-6-90-PA, which grips the cut clip, then tightens its wings and thus clamps and fully opens the clip. Finally, with an SMC model CXSM25-70 cylinder, the clip is brought closer by a precise horizontal movement to the junction point where the two seedlings to be grafted are located. At the point of clip placement, a passive fitting device is adapted to accommodate and locate the seedlings in front of the clip. To ensure a precise bond without unwanted seedling displacement, both parts remain in contact and can thus fasten the 
bond. Once the clip is placed on the seedlings, the device that kept the graft clip pinched loosens and moves away from the junction point, returning to its resting position (Figure 6).

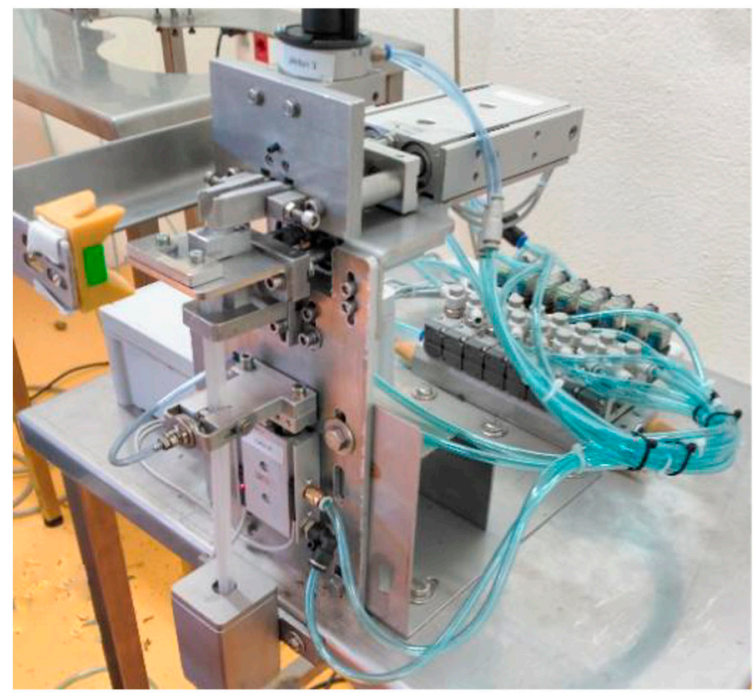

(a)

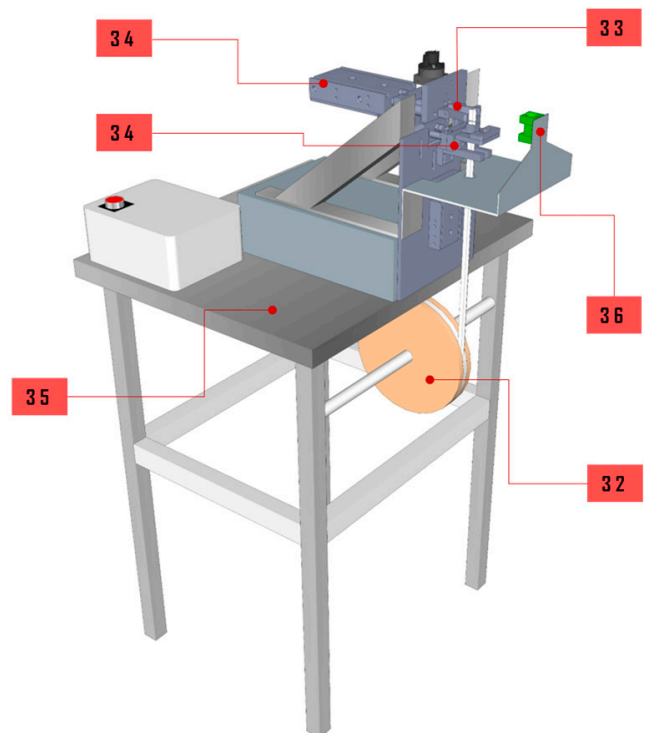

(b)

Figure 6. (a) Detailed view of the device that dispenses and places the graft clip. (b) Sketch of the device that dispenses graft clips. (31) Pneumatic cylinders and blade to make the grafting clip. (32) Continuous silicone roll for clip manufacture. (33) Tweezers for the grip and clip opening. (34) Pneumatic cylinder responsible for bringing the grafting clip closer to the junction point. (35) Worktable. (36) Plant placement device and grafting clip insertion point.

The graft is accomplished when both plants are placed in intimate contact with one another and the graft clip is pressed onto them: (6) clip preparation and placement (CPP). Once the clip is placed, the robot holding the scion releases the graft and withdraws, leaving the bonding area, while the other robot, which holds the completed graft by its lower part, moves the graft by the rootstock to the tray where the grafts will be left once finished: (7) approach the output trays (AOT). The graft is deposited in an alveolus of the output tray: (8) insertion on trays and release of plants (ITR).

Once the process is finished, both robots return to their resting positions, either as an end point or as a point of passage from where a new work cycle begins: (9) return home (RH). The process is repeated until the work trays are completed. The tray with the grafted seedlings is removed, and the grafted seedlings are subjected to a post-grafting process of healing, where their success is examined over 14 days: (10) post-graft losses (PGL). The entire system and grafting equipment described, as well as other secondary elements and auxiliary equipment, are managed and coordinated in a global manner through a central control unit, consisting of a PLC model CJ2 M, with an Omron CPU32.

During the grafting operation, 10 control points were established as singular intermediate points of reference in the process, which allowed us to record the partial times used and a distribution of failures during grafting (Figure 7).

The flowchart describing the operations and process described above allowed us to evaluate the validity and efficacy of conventional industrial robotics applied to tomato seedling grafting using external low-cost passive devices that facilitate grafting completion. The external devices act as a tool both in cutting the seedlings and in the dispensing and placing of the graft clip (Figure 8). 


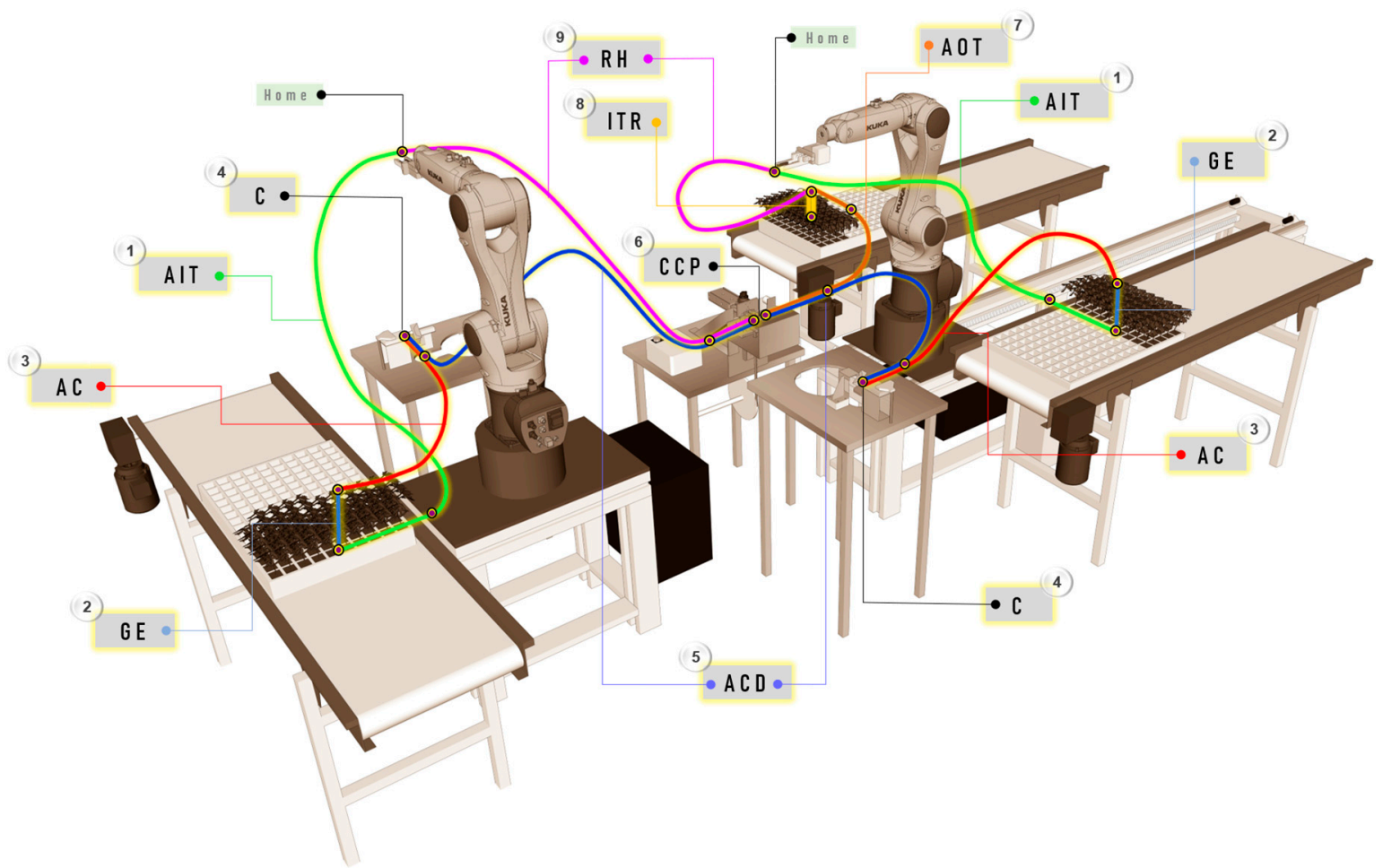

Figure 7. Travel details. Singular points: (1) approach the input trays (AIT); (2) grip and extraction (GE); (3) approach the cutting zone (AC); (4) cutting process (C); (5) approach the clip dispensing zone (ACD); (6) clip preparation and placement (CPP); (7) approach the output trays (AOT); (8) insertion on trays and release of plants (ITR); (9) return home (RH).

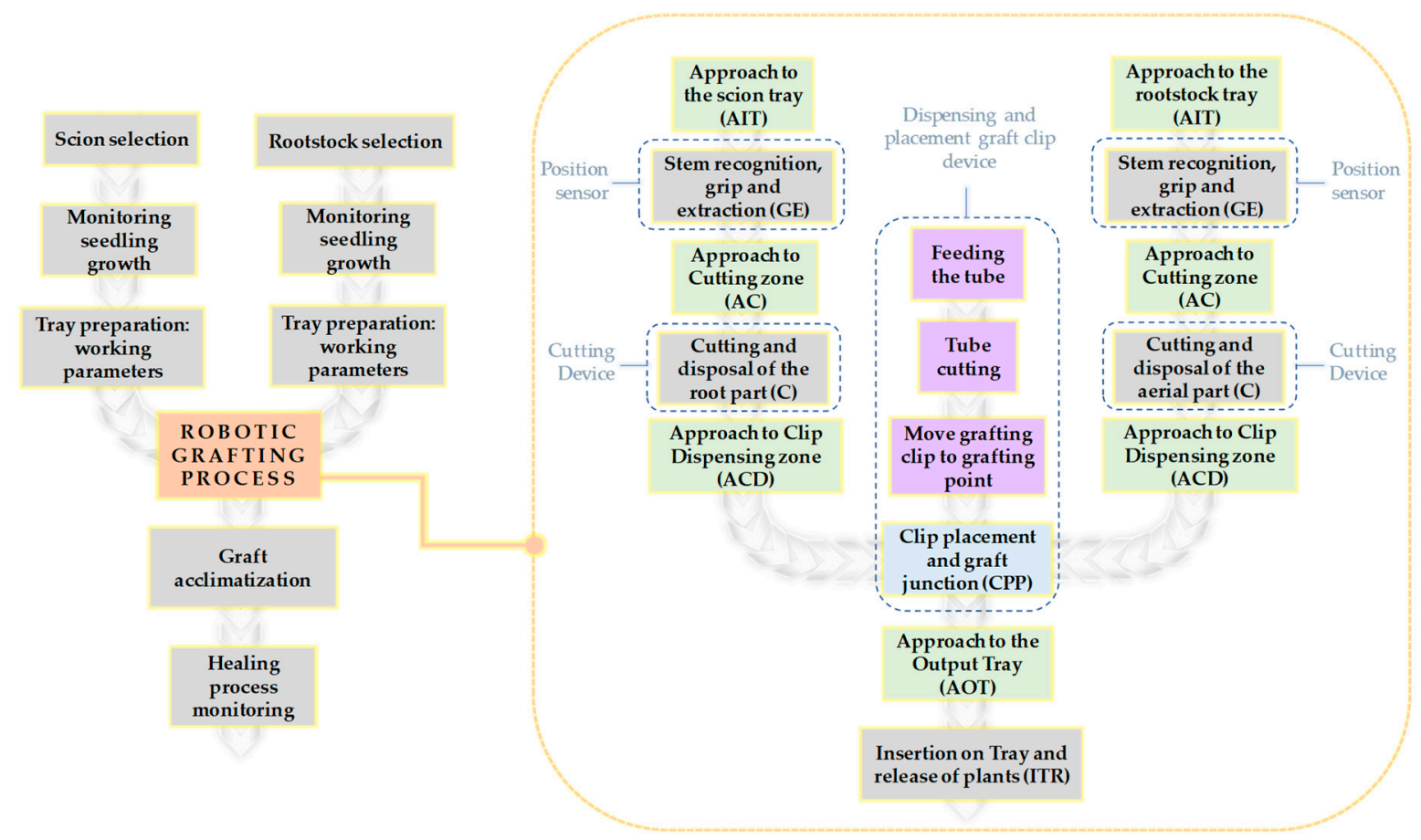

Figure 8. Flowchart of the developed automated grafting process. 


\subsection{Definition of Operating Conditions}

The experiment was conducted at the Tecnova Technological Center (Centro Tecnológico Tecnova): Foundation for Agricultural Technologies of Agriculture, in Almería $\left(36^{\circ} 52^{\prime} 38^{\prime \prime} \mathrm{N}, 2^{\circ} 19^{\prime} 59^{\prime \prime} \mathrm{W}\right.$ ) between the months of April and June 2017. The environment of Almería is a model of agricultural exploitation. Greenhouse growth of arable fruit crops has a high technical and economic performance, with tomato cultivation being of particular importance.

The rootstock used in the experiment was the interspecific hybrid "Maxifort" from De Ruiter Seed ${ }^{\mathrm{TM}}$, which is recommended for crops with better behavior at low temperatures and under high salinity conditions. The "Ventero" variety from De Ruiter Seed ${ }^{\mathrm{TM}}$ was used as an indeterminate hybrid tomato for branch harvest. Both types of seeds are routinely used in seedbeds to perform manual grafts using the "tomato on tomato" $(\mathrm{T} / \mathrm{T})$ technique, which demonstrates their prior compatibility with the robotic system.

The growth protocol developed in the nursery attempted to obtain plants that were grown and cared for until reaching a similar growth state between the rootstock and scion, with mature plants and those prepared for the graft having two-four well-defined true compound leaves [28] and stem diameters of at least $1.5 \mathrm{~mm}$ for the splicing method [29]. Therefore, stems with some natural variability characteristic of the development of each plant (between 1.5 and $2.5 \mathrm{~mm}$ in diameter in the area close to the cut for the scion, and between 2 and $3 \mathrm{~mm}$ in diameter for the area close to the cut for the rootstock) were worked with. Usually, in the automatic graft, the requirements in terms of growth and uniformity required for the rootstock and scion seedlings are as critical as in the manual graft [30], demanding an arduous previous task of pre-selection and pairing similar diameters between the linked seedlings. In our experiment, this work was eliminated because the seedlings were cut with a bevel at a $60^{\circ}$ angle. From a certain cutting angle, between $50^{\circ}$ and $70^{\circ}$, and provided that one works within the margins of natural variability between the previously established stems, the success rate of the graft was acceptable and higher than $95 \%$. Therefore, the need to seek equal diameters of the workplaces was of lessened importance [27,31].

Prior to each experiment and for each tray, it was ensured that all the alveoli slots contained seedlings that met the previously established rootstock size criteria. The environmental conditions were regulated during the grafting process, with temperatures between $20^{\circ} \mathrm{C}$ and $25^{\circ} \mathrm{C}$, conditions of relative humidity that were sometimes forced and were guaranteed to be above $75 \%$, and stable, non-direct daylight luminosity conditions.

The data were collected for each test via filming and were then timed; the times until reaching each control point of the process until the graft was completed or the point of generation of each failure were evaluated.

Regarding the post-grafting conditions, the plants began to wilt immediately after cutting and grafting, so once each graft tray was finished, it was immediately introduced into a small healing chamber consisting of a tunnel slightly larger than the dimension of each tray and a low height, covered by a transparent film. This tunnel was placed inside a chamber in which the climatic conditions were controlled throughout the healing process. During the first $48 \mathrm{~h}$, the plants were kept without illumination to reduce transpiration and evaporation. On the following days, the intensity of the light was increased, and a $14 \mathrm{~h}$ light photoperiod with a value $\approx 100 \mu \mathrm{mol} \cdot \mathrm{m}^{-2} \cdot \mathrm{s}^{-1}$ of PAR, ( $\left.3000 \mathrm{lux}\right)$ of non-direct and diffuse light was established during the callus formation stage, from LED lights, corresponding to a value slightly above the compensation point because there is evidence that a high intensity of light prevents callus formation [1]. The level of illumination was gradually increased after several days. The temperature was established with a variable set point in the healing chamber between $23^{\circ} \mathrm{C}$ and $30^{\circ} \mathrm{C}$, with an average of approximately $26^{\circ} \mathrm{C}$, slightly varying between the diurnal and nocturnal conditions. The relative humidity was initially established between $75 \%$ and $95 \%$ in an attempt to reduce the transpiration rate of the scions, avoiding high stress and thus preventing the drying of the graft [32]. The humidity level was gradually reduced in successive days to condition the grafts to the outdoors. The vapor pressure deficit (VPD), during the critical graft healing phase was 
around $0.8 \mathrm{kPa}$ in the tunnel inside of the healing chamber, with the aim of decreasing transpiration. This value was gradually increased in the following days.

The success or failure of the final graft was evaluated by estimation and visual assessment performed daily across the 14 days after grafting, assessing the natural evolution of the graft, and analyzing other symptoms and external evidence that would determine its classification as either a success or a failure. In making this determination, key intermediate points were considered to mark an inflection of the task or singularity within the process, so that the successful or unsuccessful completion of this phase of the robotic process could be evaluated.

\subsection{Experiments}

In the process, different robot working speeds were tested, with the objective of determining the influence on the graft success. The robot speeds were constant within each test and ranged from $100 \mathrm{~mm} / \mathrm{s}$ to $600 \mathrm{~mm} / \mathrm{s}$, with gradual increments of $100 \mathrm{~mm} / \mathrm{s}$. In total, six working speeds were tested.

A total of 900 grafts were prepared, divided into three experimental blocks consisting of a total of 300 grafted seedlings each, where a total of 50 grafts were performed for each of the six test rates. The sum of the experimental blocks, equal to one another, therefore consisted of a total of 150 resulting grafts for each of the six tested velocities.

Only the work times of the external processes on the seedlings (manipulations on the trays, cutting, and dispensing of the clip) were kept constant between the tests. It was understood that since the work times are based on pneumatic technology, they were optimized for the corresponding work speed at 3.5 bar $(0.35 \mathrm{MPa})$.

Each experimental block, when was developed on a specific date, was treated under the same cultivation, manipulation, and post-graft healing conditions, with the aim of matching the development conditions between the three experimental blocks. In addition, for each of the experimental blocks, the positional order of each test rate was altered, thereby neutralizing the dependence of said factor.

The statistical analysis of the collected data was performed using the software Minitab v.18.1. The obtained results were subjected to an analysis of variance with a confidence level of $95 \%$, and contrast tests were applied using Tukey's test (honestly significant difference, HSD test).

\section{Results and Discussion}

After performing the hypothesis test, we estimated that there were statistically significant differences between the grafting times used for the different tested work rates (Table 1).

For each velocity tested (between TS1 and TS6), the variability of time used in each test unit was mainly due to singularities that facilitated the manipulation and the development of the grafting work, to a greater or lesser extent. Singularities included the position of the alveolus in each row of work, the natural variability of the seedling emergence point within each alveolus, and the unique growth morphology of each seedling, among others. At low velocities, the difference for each work velocity was clear, given that the time taken to solve these singularities was less significant compared to the time spent in tasks not affected by these singularities. However, at high speeds, these factors became increasingly important and, to some extent, determined the time spent in each test unit.

Grouping the data by test speed, analyzing the failures associated with each control point that were recorded for the different velocities, and performing the hypothesis test, we estimated that, based on the Tukey's tests, there were statistically significant differences between the groups of different assay speeds (Table 2).

At low test rates, the success rate was higher, greater than $90 \%$ for speeds equal to or lower than TS3, and there was a significantly increasing graft failure for operating speeds equal to or greater than TS4. Low speeds, between TS1 and TS3, had similar behavior in terms of failures; therefore, we consider that their differences were derived from chance and not from the working speed itself. Therefore, it is clear that the TS3 production speeds are more attractive, given that they had a higher production ratio associated with a low failure rate. 
The relationship linking the number of grafts/hour for each of the tested rates (TS1 to TS6) can be considered practically linear and was only altered by the random parameters derived, to a great extent, from the natural variability of the work seedling growth. Such nuances of correction barely affected the speed, which was largely marked by that established for both robots for each test, although the working speed of the auxiliary devices was kept constant. In addition, the percentage of successes/failures associated with each of the test rates (TS1 to TS6), considering their evolution, allowed us to observe a behavior similar to a quadratic function (Figure 9).

Table 1. Comparison between the mean times spent in grafting task for the six tested speeds. Grouping of comparisons applying Tukey's HSD test (honestly significant difference). Significance level $p<0.05$.

\begin{tabular}{ccccccccc}
\hline $\begin{array}{c}\text { TS } \\
\text { (Test Speed) }\end{array}$ & $N$ & Mean Time (s) & Variance & St. Dev & SS & St. Error & 95\% CI & $\begin{array}{c}\text { Grouping } \\
\text { (Tukey's HDS) }\end{array}$ \\
\hline TS1 & 150 & 40.641 & 185.078 & 13.600 & 27576.61 & 0.617 & $(39.43 ; 41.85)$ \\
TS2 & 150 & 21.521 & 56.582 & 7.522 & 8430.76 & 0.617 & $(20.31 ; 22.73)$ \\
TS3 & 150 & 15.430 & 27.691 & 5.262 & 4125.97 & 0.617 & $(14.22 ; 16.64)$ \\
TS4 & 150 & 13.320 & 30.922 & 5.561 & 4607.40 & 0.617 & $(12.11 ; 14.53)$ & B \\
TS5 & 150 & 9.416 & 19.950 & 4.467 & 2972.62 & 0.617 & $(8.20 ; 10.63)$ & C \\
TS6 & 150 & 6.993 & 22.708 & 4.765 & 3383.49 & 0.617 & $(5.78 ; 8.20)$ \\
\hline
\end{tabular}

The different letters show significative differences.

Table 2. Comparison between the means for grafting failures for the six speeds tested. Grouping of comparisons applying Tukey's HSD test (honestly significant difference). Significance level $p<0.05$.

\begin{tabular}{cccccccc}
\hline $\begin{array}{c}\text { TS } \\
\text { Test Speed) }\end{array}$ & $\begin{array}{c}\text { Speed } \\
(\mathbf{m m} / \mathbf{s})\end{array}$ & $\begin{array}{c}\text { Check } \\
\text { Points }\end{array}$ & $\begin{array}{c}\text { Mean } \\
\text { (Fails) }\end{array}$ & Variance & St. Dev & $\mathbf{9 5 \%}$ CI & $\begin{array}{c}\text { Grouping } \\
\text { (Tukey HDS) }\end{array}$ \\
\hline TS1 & 100 & 10 & 1.50 & 3.16667 & 1.780 & $(0.022 ; 2.978)$ & $\mathrm{A}$ \\
TS2 & 200 & 10 & 1.60 & 3.37778 & 1.838 & $(0.122 ; 3.078)$ & $\mathrm{A}$ \\
TS3 & 300 & 10 & 1.50 & 3.16667 & 1.780 & $(0.022 ; 2.978)$ & $\mathrm{A}$ \\
TS4 & 400 & 10 & 2.20 & 6.17778 & 2.486 & $(0.722 ; 3.678)$ & $\mathrm{AB}$ \\
TS5 & 500 & 10 & 2.70 & 5.37778 & 2.319 & $(0.922 ; 3.878)$ & $\mathrm{AB}$ \\
TS6 & 600 & 10 & 4.70 & 11.34444 & 3.370 & $(3.220 ; 6.180)$ & $\mathrm{B}$ \\
\hline
\end{tabular}

The different letters show significative differences.

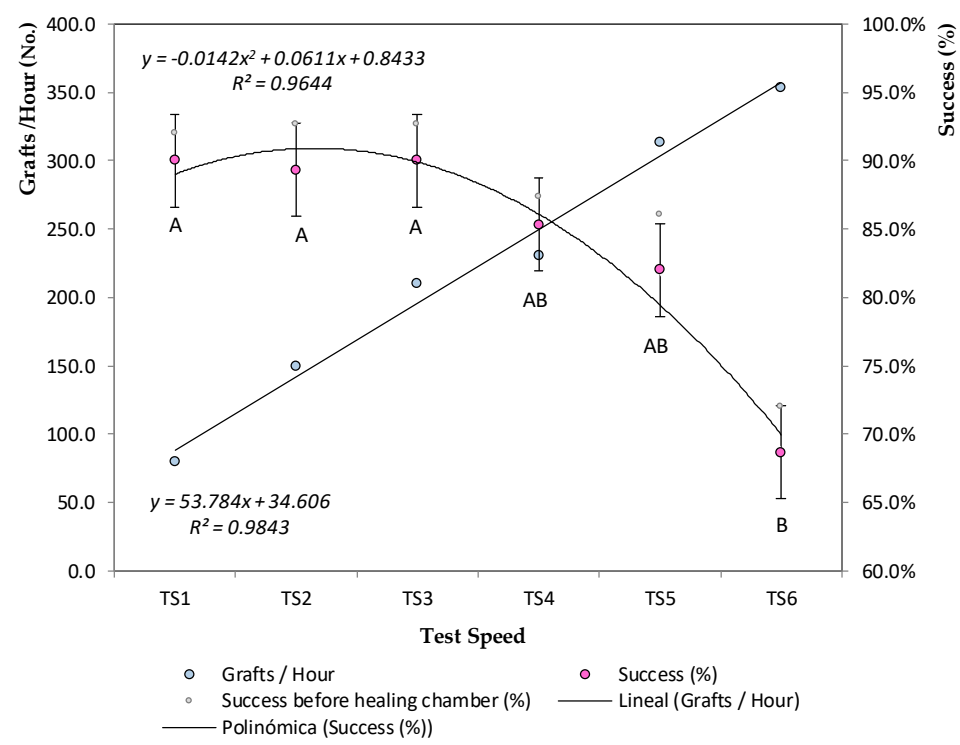

Figure 9. Grafts/hour versus grafting success for different test speeds (TS1 to TS6). Success rate includes the typical error. "Success before healing chamber" has been included to evaluate the influence on the global success of the grafting process. 
At the working speeds of the TS3 and TS4 robots (210 and 240 grafts/hour, respectively), the number of grafts estimated for manual expert workers was already surpassed, i.e., a maximum of 150-240 grafts/hour [7,15], and an average of approximately no more than 1000 grafts per person per day $[30,33,34]$. In addition, the success rates for manual grafting are not usually very high, between $81 \%$ and $91 \%$ [35]. In part, this rate of failure may come from long hours in a hostile work environment, characterized by high humidity and temperature. The success rates achieved by the robotic graft were quite similar to those achieved by manual workers, reaching $90.0 \%$ for the TS3 speed of $300 \mathrm{~mm} / \mathrm{s}$ and $85.3 \%$ for the TS4 speed of $400 \mathrm{~mm} / \mathrm{s}$.

For large cutting angles in splicing grafts, the difference between the diameters of the linked stems became less important as long as they stayed within certain a range [31]. For cuts at a $60^{\circ}$ bevel, failure in the healing and grafting of the middle graft was between $3 \%$ and $6 \%$ of failures [27]. The difference between the number of successes considered after grafting and the number of successes recorded after the healing period in the chamber confirmed this parameter (less than $4 \%$ ), and except for errors not visually detected in the grafting process, we associated the percentage of losses in the chamber to random problems in the healing process itself.

The established isolated intermediate control points allowed us to record the cause for each failed graft. Studying the origin of the graft failures associated with each velocity in detail, we determined that at low test rates, the failures detected in the grafting process in the GE phase (grip and extraction) were slightly more significant. This result may be because the seedling, when extracted from its alveolus at a lower velocity, experiences lower extraction acceleration, with a consequently greater resistance and grip to the alveolus walls. As a result, the roots tend to remain adhered and occasionally incur damage and tears; traction damage to the stem or alterations to the other plants in the tray may also occur, among other problems.

However, it was observed that, as the test speed increased, the number of failures in this phase decreased, as did the number of failures in the operations of adaptation and placement of the seedlings, such as the AC (approach the cutting zone) and ACD (approach the clip dispensing zone) phases, and in the tasks properly conducted by these tools: C (cutting process) and CPP (clip preparation and placement). In part, this was due to seedling management from certain working speeds, where there was a substantial acceleration in the displacements between points, and with it, the inertia experienced on the seedlings, which, together with their root ball (semi-compressed coconut fibre substrate) could suffer greater damage and tearing when experiencing such sudden changes of state. In addition, it was observed that high accelerations led to excessive seedling balance by the ends not held by the robot clamp (root ball and stem), causing the robot to lose its reference point at rest or to not return to it in time, thus spoiling the graft. The development of the grafting process is shown in Figure 10.

As the working speed increased, the times spent in the tasks performed by the external working tools became more important compared to the times spent in the displacement and pre-positioning of the seedlings in front of the tools. This factor is due to the fixed value of the velocities of the pneumatic devices in response to an incremental increase in the robot velocities (Figure 11).

At speeds equal to or lower than TS3, the recorded success rate was relatively good at approximately $90 \%$, but it decreased substantially at higher speeds. The next tested speed, TS4, had a significantly different percentage of recorded failure, five points lower or $85.3 \%$. It is important to assess the success associated with each work rate, because it is the factor that makes it feasible as an alternative to manual grafting, because the system evaluated is scalable in terms of systems and tools operating in parallel. That is, the clamp or end element could be adapted by cloning two or more gripping systems in parallel for the seedlings, and, to the same extent, the auxiliary devices or tools acting on the seedlings could be cloned, thus multiplying the number of plants grafted per hour, maintaining similar success rates. In addition, regarding these working speeds (TS3 and TS4), the number of grafts capable of being developed manually began to be exceeded. Therefore, when evaluating the grafts/success ratio, we estimated a better average behavior for velocities close to TS3 (210 grafts/hour). 


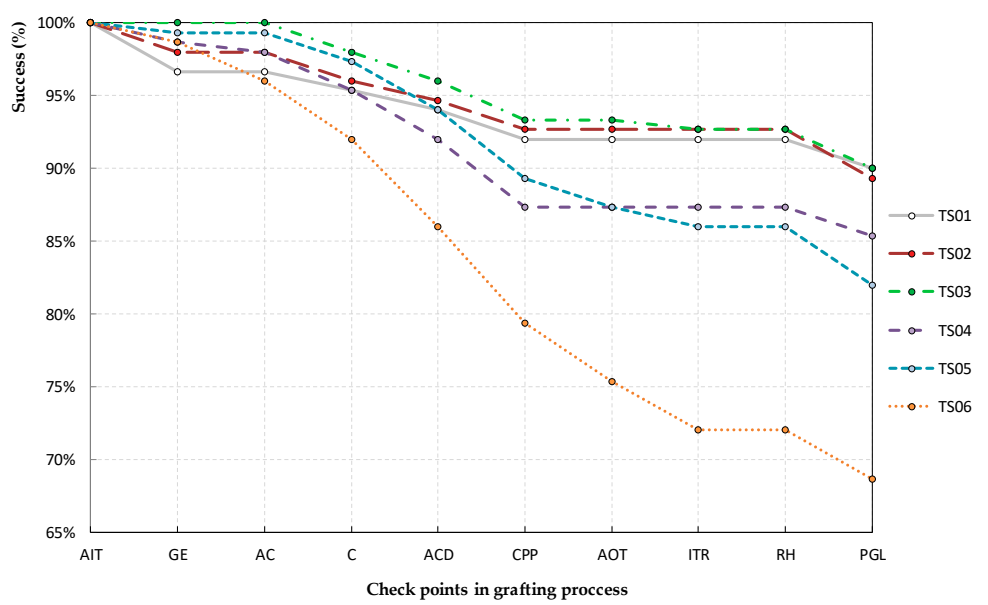

Figure 10. Success associated with each check point for the different test speeds, reflected in a percentage of successful plants in the grafting process. Check Points: approach the input trays (AIT), grip and extraction (GE), approach the cutting zone (AC), cutting process (C), approach the clip dispensing zone (ACD), clip preparation and placement (CPP), approach the output trays (AOT), insertion on trays and release of plants (ITR), return home (RH), and post-graft losses (PGL).

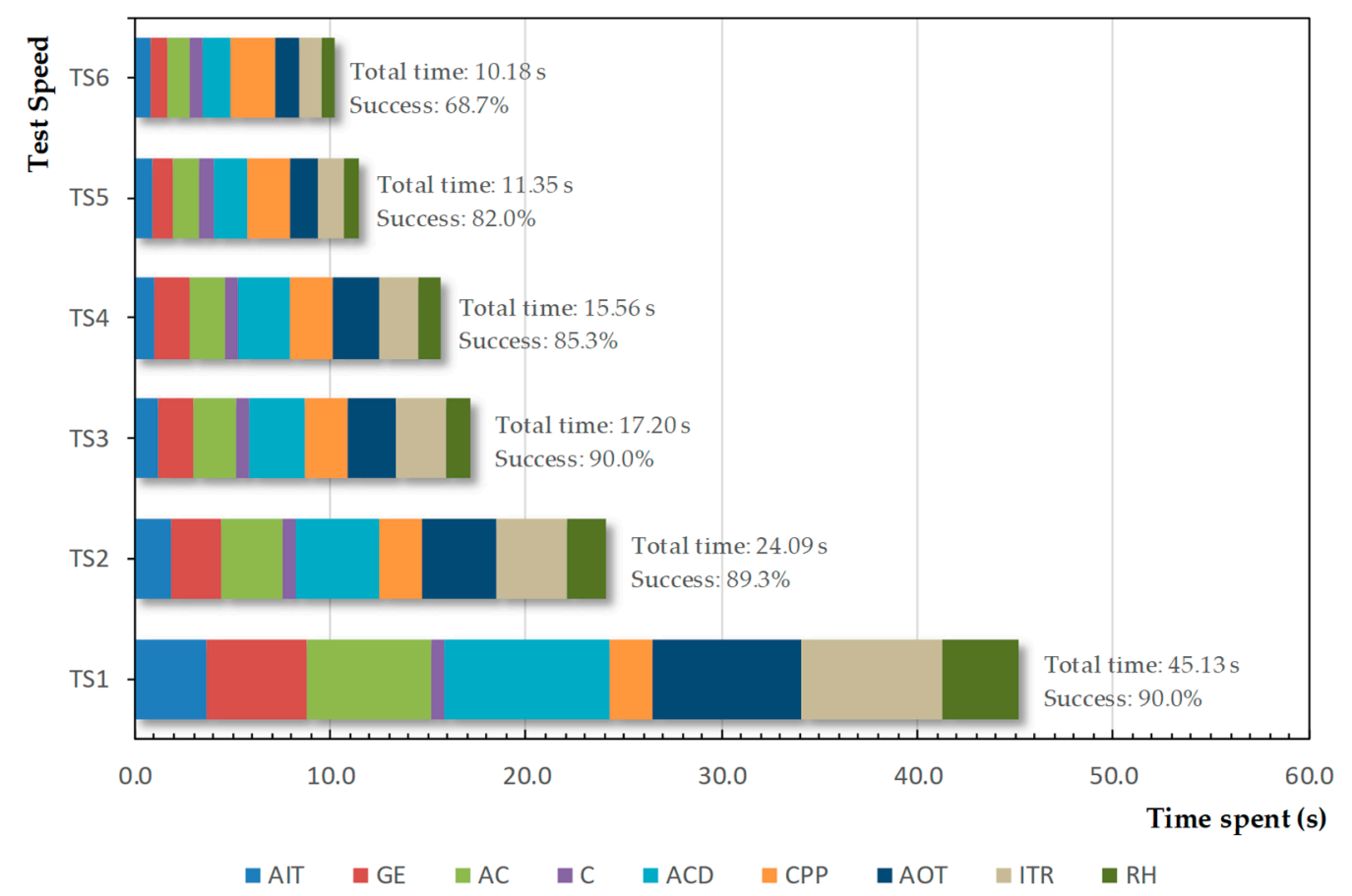

Figure 11. Average time spent in the development of each phase between control points. Check Points: approach the input trays (AIT), grip and extraction (GE), approach the cutting zone (AC), cutting process $(\mathrm{C})$, approach the clip dispensing zone (ACD), clip preparation and placement (CPP), approach the output trays (AOT), insertion on trays and release of plants (ITR), and return home (RH).

Numerous studies have collected the test results of prototypes and commercial devices for the automated grafting of horticultural seedlings over the last three decades $[3,5,7,23,36-44]$, and the results for dozens of pieces of equipment have been collected, mainly from Southeast Asia (Japan, Korea, and China mainly) and Europe.

Comparatively, we can refer to four factors that determine the convenience of and interest in the study equipment compared to other existing equipment: (a) the flexibility in terms of the horticultural family of work and the grafting method developed; (b) the degree of automation and the number of 
operators involved in the process; (c) system velocity (grafts/hour) and system efficiency; and (d) the price of the equipment.

(a) There are devices prepared exclusively for use with Solanaceae and others that allow working with Solanaceae and Cucurbitaceae. These pieces of equipment are mostly characterized by being inflexible. The study equipment, based on industrial robotics supported by low-cost external equipment, is specifically intended for splicing grafts, but enables easy and economic reconversion and readaptability, as it is able to work with other horticultural families and to apply other grafting methods. It even has the ability to perform other tasks in the seedbeds or productive environments.

(b) The existing prototypes and commercial devices present a different degree of automation, ranging from simple tools to help with grafting (cutting or dispensing the clip), to semi-automated equipment that requires the participation of two to three operators, to fully equipped devices. These are all automated and can be managed by a single operator. Nevertheless, they claim a high homogeneity in the work seedlings, requiring the important tasks of pre-sorting and pairing between seedlings, which to some extent tarnishes the autonomy of the system. The study equipment, by working with a high cutting angle, allowed us to avoid these previous tasks of searching and matching between the diameters of the workplaces and therefore enjoys a high degree of autonomy.

(c) Regarding the number of grafts per hour, the majority of studies present equipment ranging between 200 and 1200 grafts/hour. These values are much higher than those achieved using this equipment (210-240 grafts/hour), but these results are sufficient compared to manual grafting, and improvement is feasible by replicating terminal systems, allowing for working in parallel and over several plants simultaneously. In contrast, the system has a high success rate or efficiency of approximately $90 \%$.

(d) The current price trend of industrial robotics, together with the use of simple, low-cost auxiliary equipment, allows us to estimate that the studied system is a rapidly amortizable system, with an initial investment in robots no greater than the biannual cost associated with the minimum interprofessional wage in countries [25], and an additional base cost of auxiliary and control equipment which is not higher than other interprofessional minimum wages (MW). This implies a total base investment of 5 MW ( $€ 60,000)$. Faced with this, the estimated costs of high automation systems robotic equipment in high productivity environments (100 million plants per year) are estimated at investments above $\sim \$ 7,500,000$ [45]. Comparatively, and estimating our system working at approximately 230 grafts/hour, we would yield approximately 2 million grafts per year per piece of equipment, which would imply approximately 50 systems working in parallel to reach 100 million grafts. Such scaling would involve an investment of $\sim € 3,000,000$, well below the investment necessary for other robotic equipment.

\section{Conclusions}

The splicing technique, widely used for Solanaceae such as tomato, has the advantage of being simple and methodical, and therefore easily automatable. In the last three decades, there have been numerous attempts to develop equipment to deal with the automated grafting of horticultural plants, and the challenge of using conventional industrial robotics to perform the splicing graft process can provide a great opportunity. The robotic cell tested herein is based on two industrial robots and low-cost passive auxiliary units.

The use of low speeds, between $100 \mathrm{~mm} / \mathrm{s}$ and $300 \mathrm{~mm} / \mathrm{s}$, allows ratios close to a $90 \%$ success rate to be maintained. At medium-high velocities, between $400 \mathrm{~mm} / \mathrm{s}$ and $500 \mathrm{~mm} / \mathrm{s}$, success ratios were still acceptable above $80 \%$. However, at a test speed of $600 \mathrm{~mm} / \mathrm{s}$, there was a considerable decrease in the success rate to less than $70 \%$.

Consequently, we conclude that it is advisable to use a velocity close to $300 \mathrm{~mm} / \mathrm{s}$ (90.0\% success), which allows working at speeds higher than those estimated for manual expert workers, approximately 150-240 grafts/hour (with success rates between $81 \%$ and $91 \%$ ). Decreasing the work rate below that point did not substantially improve the success rate. 
Author Contributions: J.-L.P.-A. conceived and designed the experiments, performed the experiments, collected and analyzed the data, interpreted the results and developed the manuscript. Á.C.-O. conceived and designed the experiments, analyzed the data, interpreted the results and developed the manuscript. C.-C.M.-G. conceived, designed and performed the experiments. I.G. and M.G.G. provided constructive suggestions on experiment analysis.

Funding: This research received no external funding.

Acknowledgments: This study was supported by Tecnova, Technological Center: Foundation for Auxiliary Technologies for Agriculture. The authors would like to acknowledge all the employees involved for their contributions to the experimental setting and data collection.

Conflicts of Interest: The authors declare no conflicts of interest.

\section{References}

1. Hartmann, H.; Kester, D.E.; Davies, F.T.; Geneve, R.L. Principles of grafting and budding. In Plant Propagation: Principles and Practices, 8th ed.; Prentice Hall: Upper Saddle River, NJ, USA, 2010; Chapter 11.

2. Camacho-Ferre, F. El injerto en tomate como alternativa al bromuro de metilo. Experiencias con esta técnica en San Quintín. B.C.-México. II Agro Simp. Int. Téc. Empres. Prod. y Tendencias 2013, 1-3. Available online: http://203.187.160.132:9011/simm.cicese.mx/c3pr90ntc0td/horta/docs/camachoFerre.pdf (accessed on 15 July 2019).

3. Lee, J.-M.; Oda, M. Grafting of Herbaceous Vegetable and Ornamental Crops, Horticultural Reviews. Hortic. Rev. 2003, 28, 61-124. [CrossRef]

4. Sakata, Y.; Ohara, T.; Sugiyama, M. The history and present state of the grafting of Cucurbitaceous vegetables in Japan. III Int. Symp. Cucurbits 2007, 159-170. [CrossRef]

5. Lee, J.-M.; Kubota, C.; Tsao, S.J.; Bie, Z.; Echevarria, P.H.; Morra, L.; Oda, M. Current status of vegetable grafting: Diffusion, grafting techniques, automation. Sci. Hortic. 2010, 127, 93-105. [CrossRef]

6. Rivard, C.L.; Sydorovych, O.; O'Connell, S.; Peet, M.M.; Louws, F.J. An economic analysis of two grafted tomato transplant production systems in the United States. Horttechnology 2010, 20, 794-803. [CrossRef]

7. Lin, H.-S.; Chang, C.-Y.; Chien, C.-S.; Chen, S.-F.; Chen, W.-L.; Chu, Y.-C.; Chang, S.-C. Current Situation of Grafted Vegetable Seedling Industry and Its Mechanization Development in Taiwan. 2016, pp. 65-76. Available online: http://www.fftc.agnet.org/activities.php?func=view\&id=20160113155600 (accessed on 15 July 2019).

8. Djidonou, D.; Gao, Z.; Zhao, X. Economic analysis of grafted tomato production in sandy soils in northern Florida. Horttechnology 2013, 23, 613-621. [CrossRef]

9. Rysin, O.; Rivard, C.; Louws, F.J. Is vegetable grafting economically viable in the United States: Evidence from four different tomato production systems. Acta Hortic. 2015, 1086, 79-86. [CrossRef]

10. Singh, H.; Kumar, P.; Chaudhari, S.; Edelstein, M. Tomato Grafting: A Global Perspective. HortScience 2017, 52, 1328-1336. [CrossRef]

11. De Miguel, A. Use of Grafted Plants and I.P.M. Methods for the Production of Tomatoes in the Mediterranean Region; Instituto Valenciano de Investigaciones Agrarias: Valencia, Spain, 2004; Available online: http: //ec.europa.eu/clima/events/docs/0014/tomato_4_en.pdf (accessed on 15 July 2019).

12. De Miguel, A. Evolución del injerto de hortalizas en España. Technol. Hortícola Hortic. Int. 2009, 10, 72. Available online: http://www.horticom.com/revistasonline/horticultura/rhi72/10_17.pdf (accessed on 15 July 2019).

13. González, F.M.; Hernández, A.; Casanova, A.; Depestre, T.; Gómez, L.; Rodríguez, M.G. El injerto herbáceo: Alternativa para el manejo de plagas del suelo. Rev. Protección Veg. 2008, 23, 69-74, ISSN 2224-4697. Available online: http://www.shorturl.at/klAKU (accessed on 15 July 2019).

14. Hoyos Echevarria, P. Situación del injerto en horticultura en España: especies, zonas de producción de planta, portainjertos. Ind. Hortícola 2007, 199, 12-25. Available online: http://www.horticom.com/revistasonline/ horticultura/rh199/12_25.pdf (accessed on 15 July 2019).

15. Ngo, Q.V. Grafted Tomato in Vietnam, From 0 to 7000 Ha/Year. 2016. Available online: http://www.fftc.agnet: htmlarea_file/activities/20160113155600/2016P032-7VN.pdf (accessed on 15 July 2019).

16. Kobayashi, K.; Suzuki, M.C. Grafting Robot. J. Robot. Mechatron. 1999, 11, 213-219. [CrossRef] 
17. Tian, S.; Xu, D. Current status of grafting robot for vegetable. In Proceedings of the 2011 International Conference on Electronic \& Mechanical Engineering and Information Technology, Harbin, China, 12-14 August 2011; Volume 4, pp. 1954-1957. [CrossRef]

18. Chiu, Y.C.; Chen, S.; Chang, Y.C. Development of a circular grafting robotic system for watermelon seedlings. Appl. Eng. Agric. 2011, 10, 95-102. [CrossRef]

19. Kim, H.M.; Hwang, S.J. Comparison of Pepper Grafting Efficiency by Grafting Robot. Prot. Hortic. Plant Fact. 2015, 24, 57-62. [CrossRef]

20. Oda, M. Grafting of Vegetables to Improve Greenhouse Production. Ph.D. Thesis, Food \& Fertilizer Technology Center: College of Agriculture, Osaka Prefecture University, Sakai Osaka, Japan, 1998; pp. 1-11. Available online: http://www.agnet:library.php?func=view\&id=20110803135029/ (accessed on 15 July 2019).

21. De Miguel, A.; Cebolla, V. Unión del injerto. Terralia 2005, 53, 50-60. Available online: https://www.terralia. com/terralias/view_report?magazine_report_id=365 (accessed on 15 July 2019).

22. Chiu, Y.; Chen, S.; Chang, Y.; Chou, L. Development of Robotic Grafting Systems for Fruit Vegetable Seedlings. In Proceedings of the FFTC \& Tainan-DARES International Workshop on Grafting to Improve Fruit Vegetable Production, Tainan, Taiwan, 16-20 May 2016; pp. 77-85. Available online: http://www.fftc.agnet: library.php?func=view\&style=type\&id=20170331104933 (accessed on 15 July 2019).

23. Jinyuan, Z.; Yunsheng, T. Development Status of Internal and External Graft Machinery. Council Agric. For. 2015, 99-106. Available online: https://book.tndais.gov.tw/Other/2015seedling/speech10.pdf (accessed on 15 July 2019).

24. Kuka Robots Ibérica. In Proceedings of the Conference Universidad de Vigo, Vigo, Spain, 27 October 2008; Available online: http://shorturl.at/yUVY9 (accessed on 15 July 2019).

25. Chiacchio, F.; Petropoulos, G.; Pichler, D. The Impact of Industrial Robots on EU Employment and Wages: A Local Labour Market Approach; Bruegel: Brussel, Belgium, 2018; pp. 1-18.

26. Feng-feng, W. Study on Grafting Machine of Camellia Seedling for Cleft Grafting. Ph.D. Thesis, Chinese Academy of Sciences, Beijing, China, 2011. Available online: https://www.dissertationtopic.net/doc/149228 (accessed on 15 July 2019).

27. Pardo-Alonso, J.-L.; Carreño-Ortega, Á.; Martínez-Gaitán, C.-C.; Callejón-Ferre, Á.-J. Combined Influence of Cutting Angle and Diameter Differences between Seedlings on the Grafting Success of Tomato Using the Splicing Technique. Agronomy 2018, 9, 5. [CrossRef]

28. Miles, C.; Flores, M.; Estrada, E. Injerto de Verduras Berenjenas y Tomates. In Hoja de Datos de la Extensión, FS052ES; Washington State University: Washington, DC, USA, 2013; pp. 1-4. Available online: https://s3.wp. wsu.edu/uploads/sites/2071/2014/04/Grafting-Eggplants-and-Tomatoes-SPAN-FS052ES.pdf (accessed on 15 July 2019).

29. Bumgarner, N.R.; Kleinhenz, M.D. Grafting Guide: A Pictorial Guide to the Cleft and Splice Graft Methods as Applied to Tomato and Pepper; Ohio State University, Research and Development Center: Columbus, OH, USA, 2014; Available online: http://www.walterreeves.com/wp-content/uploads/2010/11/tomato-grafting-guide. compressed.pdf (accessed on 15 July 2019).

30. Hassell, R.L.; Memmott, F.; Liere, D.G. Grafting methods for watermelon production. HortScience 2008, 43, 1677-1679. [CrossRef]

31. Bausher, M.G.; Road, S.R.; Pierce, F. Graft Angle and Its Relationship to Tomato Plant Survival. HortScience 2013, 48, 34-36. [CrossRef]

32. Johnson, S.J.; Miles, C.A. Effect of healing chamber design on the survival of grafted eggplant, tomato, and watermelon. Horttechnology 2011, 21, 752-758. [CrossRef]

33. Rivard, C.L. Tomato Grafting for High Tunnel Production; Kansas State University, Research and Extension: Manhattan, KS, USA, 2012; Available online: https://www.slideshare.net/UMNfruit/rivard-mn-ht2012a (accessed on 15 July 2019).

34. Tirupathamma, T.L.; Ramana, C.V.; Naidu, L.N.; Sasikala, K. Vegetable Grafting: A Multiple Crop Improvement Methodology. Curr. J. Appl. Sci. Technol. 2019, 33, 1-10. [CrossRef]

35. Sarah, A. Masterson. Propagation and Utilization of Grafted Tomatoes in the Great Plains; University of Alabama: Tuscaloosa, AL, USA, 2010; Available online: https://core.ac.uk/download/pdf/18529369.pdf (accessed on 15 July 2019).

36. Al-Razaq, A.H.A. Grafting techniques in vegetables crops: A review. Plant Arch. 2019, 19, 49-51. Available online: http://plantarchives:PDF\%2019-1/49-51\%20(4756).pdf (accessed on 15 July 2019). 
37. Tian, S.; Ashraf, M.A.; Kondo, N.; Shiigi, T.; Momin, M.A. Optimization of Machine Vision for Tomato Grafting Robot. Sens. Lett. 2013, 11, 1190-1194. [CrossRef]

38. Yinghui, M.; Xiwen, L. Root Pruning and Hole-Oblique Insertion Hypocotyl Automatic Grafting of Cucurbitaceous Vegetables; Chinese Society of Agricultural Engineering: Beijing, China, 2011; pp. 2-7. Available online: http://www.tcsae.org/nygcxb/ch/reader/view_abstract.aspx?file_no=X201102006\&flag=1 (accessed on 15 July 2019).

39. Song, G.; Linbin, J. Development of domestic and foreing vegetable grafting robot. J. Northeast Agric. Univ. 2007, 38, 847-851.

40. Oda, M. Use of Grafted Seedlings for Vegetable Production in Japan. Acta Hortic. 2008, 770, 15-20. [CrossRef]

41. Yamada, H. Research for Development of the Grafting Robot for Solanaceae. Tech. Pap. Agric. Mach. Res. Assoc. 2003, 65, 142-149. [CrossRef]

42. Lee, J.-M.; Bang, H.J.; Ham, H.S. Grafting of Vegetables. Jpn. Soc. Agric. Mach. Food Eng. 1998, 67, $1098-1104$. [CrossRef]

43. Hwang, H.H. Study on Development of Automatic Grafting System for Fruit Bearing Vegetable Seedling; Escuela de Silvicultura de La Universidad Sungkyunkwan-Ministro de Agricultura y Silvicultura, Sungkyunkwan: Seoul, Korea, 1997.

44. Kurata, K. Cultivation of grafted Vegetables 2. Development of Grafting Robots in Japan. HortScience 1994, 29, 240-244. [CrossRef]

45. Lewis, M.D.; Kubota, C.; Tronstad, R. Scenario-Based Economic Analyses of Different Grafting Operation Sizes. Poster, (Table 2), 1000. 2012. Available online: http://www.vegetablegrafting:wp/wp-content/uploads/ 2012/11/Lewis_poster.pdf (accessed on 15 July 2019).

(C) 2019 by the authors. Licensee MDPI, Basel, Switzerland. This article is an open access article distributed under the terms and conditions of the Creative Commons Attribution (CC BY) license (http://creativecommons.org/licenses/by/4.0/). 